\title{
Complete genome sequence of Ignisphaera aggregans type strain (AQ1.S1 $\left.{ }^{\mathrm{T}}\right)$
}

\author{
Markus Göker ${ }^{1}$, Brittany Held ${ }^{2,4}$, Alla Lapidus ${ }^{2}$, Matt Nolan², Stefan Spring ${ }^{1}$, Montri \\ Yasawong ${ }^{3}$, Susan Lucas ${ }^{2}$, Tijana Glavina Del Rio' ${ }^{2}$, Hope Tice ${ }^{2}$, Jan-Fang Cheng ${ }^{2}$, Lynne \\ Goodwin $^{2,4}$, Roxanne Tapia ${ }^{2,4}$, Sam Pitluck ${ }^{2}$, Konstantinos Liolios ${ }^{2}$, Natalia Ivanova ${ }^{2}$, \\ Konstantinos Mavromatis ${ }^{2}$, Natalia Mikhailova ${ }^{2}$, Amrita Pati ${ }^{2}$, Amy Chen ${ }^{5}$, Krishna Palaniap- \\ pan $^{5}$, Evelyne Brambilla ${ }^{1}$, Miriam Land ${ }^{2,6}$, Loren Hauser ${ }^{2,6}$, Yun-Juan Chang ${ }^{2,6}$, Cynthia D. \\ Jeffries ${ }^{2,6}$, Thomas Brettin ${ }^{2}$, John C. Detter ${ }^{2}$, Cliff Han ${ }^{2}$, Manfred Rohde ${ }^{3}$, Johannes Sikorski ${ }^{1}$, \\ Tanja Woyke ${ }^{2}$, James Bristow ${ }^{2}$, Jonathan A. Eisen ${ }^{2,7}$, Victor Markowitz ${ }^{5}$, Philip Hugenholtz ${ }^{2}$, \\ Nikos C. Kyrpides ${ }^{2}$, and Hans-Peter Klenk ${ }^{*}$ \\ ${ }^{1}$ DSMZ - German Collection of Microorganisms and Cell Cultures GmbH, Braunschweig, \\ Germany \\ ${ }^{2}$ DOE Joint Genome Institute, Walnut Creek, California, USA \\ ${ }^{3}$ HZI - Helmholtz Centre for Infection Research, Braunschweig, Germany \\ ${ }^{4}$ Los Alamos National Laboratory, Bioscience Division, Los Alamos, New Mexico, USA \\ ${ }^{5}$ Biological Data Management and Technology Center, Lawrence Berkeley National \\ Laboratory, Berkeley, California, USA \\ ${ }^{6}$ Oak Ridge National Laboratory, Oak Ridge, Tennessee, USA \\ ${ }^{7}$ University of California Davis Genome Center, Davis, California, USA \\ *Corresponding author: Hans-Peter Klenk
}

Keywords: hyperthermophile, obligately anaerobic, moderately acidophilic, fermentative, cocci-shaped, hot spring, Crenarchaeota, Desulfurococcaceae, GEBA

Ignisphaera aggregans Niederberger et al. 2006 is the type and sole species of genus Ignisphaera. This archaeal species is characterized by a coccoid-shape and is strictly anaerobic, moderately acidophilic, heterotrophic hyperthermophilic and fermentative. The type strain $\mathrm{AQ1} 1 . \mathrm{S1}^{\top}$ was isolated from a near neutral, boiling spring in Kuirau Park, Rotorua, New Zealand. This is the first completed genome sequence of the genus Ignisphaera and the fifth genome (fourth type strain) sequence in the family Desulfurococcaceae. The $1,875,953$ bp long genome with its 2,009 protein-coding and 52 RNA genes is a part of the Genomic Encyclopedia of Bacteria and Archaea project.

\section{Introduction}

Strain AQ1.S1 ${ }^{\mathrm{T}}$ (= DSM $17230=$ JCM 13409) is the type strain of the species Ignisphaera aggregans, which is the type species of the genus Ignisphaera [1], one out of nine genera in the family Desulfurococcaceae [2-5]. The generic name derives from the Latin word 'ignis' meaning 'fire', and 'sphaera' meaning 'ball', referring to coccoid cells found in the high-temperature environment such as hot springs [1]. The species epithet is derived from the Latin word 'aggregans' meaning 'aggregate forming or aggregating clumping', referring to the appearance of the cells when grown on mono-, dior polysaccharides [1]. Strain AQ1.S1 ${ }^{\mathrm{T}}$ is of particular interest because it is able to ferment quite a number of polysaccharides and complex proteinaceous substrates [1]. Here we present a summary classification and a set of features for I. aggregans AQ1.S1T, together with the description of the complete genomic sequencing and annotation.

\section{Classification and features}

Strain AQ1.S1 ${ }^{\mathrm{T}}$ was isolated from a near neutral, boiling spring situated in Kuirau Park, Rotorua, New Zealand [1]. Interestingly, strains of I. aggregans could not be cultivated from pools with similar characteristics in Yellowstone National Park [1]. Only three cultivated strains are reported for the species I. aggregans in addition to AQ1.S1", 
these are strains Tok37.S1, Tok10A.S1 and Tok1 [1]. The $16 \mathrm{~S}$ rRNA sequence of AQ1.S1 $1^{\mathrm{T}}$ is $99 \%$ identical to Tok37.S1, 98\% to Tok10A.S1 and 98\% to Tok1. Sequence similarities between strain AQ1.S1 ${ }^{\mathrm{T}}$ and members of the family Pyrodictiaceae range from $93.0 \%$ for Pyrodictium occultum to 93.4\% for P. abyssi [6] but from $89.7 \%$ for Ignicoccus islandicus to $93.5 \%$ for Staphylothermus hellenicus [6] with members of the family Desulfurococcaceae in which I. aggregans is currently classified (Table 1). Genbank [16] currently contains only three $16 \mathrm{~S}$ rRNA gene sequences with significantly high identity values to strain AQ1.S1T: clone YNP_BP_A32 (96\%, DQ243730) from hot springs of Yellowstone National Park, clone SSW_L4_A01 (95\%, EU635921) from mud hot springs, Nevada, USA, and clone DDP-A02 (94\%, AB462559) from a Japanese alkaline geothermal pool, which does not necessarily indicate the presence of I. aggregans but probably the presence of yet to be identified other species in the genus Ignisphaera. Environmental samples and metagenomic surveys featured in Genbank contain not a single sequence with $>87 \%$ sequence identity (as of June 2010), indicating that I. aggregans might play a rather limited and regional role in the environment.

The cells of strain $\mathrm{AQ1.S1}{ }^{\mathrm{T}}$ are regular to irregular cocci which occur singly, in pairs or as aggregates of many cells [1]. They usually have dimensions between 1-1.5 $\mu \mathrm{m}$ (Figure 1). Aggregation of cells is common when AQ1.S1T is grown on mono-, dior polysaccharides [1]. Strain AQ1.S1 ${ }^{\mathrm{T}}$ is hyper- thermophilic and grows optimally between $92^{\circ} \mathrm{C}$ and $95^{\circ} \mathrm{C}$, the temperature range for growth is 85$98^{\circ} \mathrm{C}$. The $\mathrm{pH}$ range for growth is $5.4-7.0$, with an optimum at $\mathrm{pH} 6.4$. The strain grows in the presence of up to $0.5 \% \mathrm{NaCl}$, however, it grows optimally without $\mathrm{NaCl}$. The doubling time is $7.5 \mathrm{~h}$ under optimal conditions [1]. I. aggregans strain $\mathrm{AQ1.S1} 1^{\mathrm{T}}$ is strictly anaerobic and grows heterotrophically on starch, trypticase peptone, lactose, glucose, konjac glucomannan, mannose, galactose, maltose, glycogen, and $\beta$-cyclodextrin. Growth on beef extract and glucose is weak and not observed on yeast extract, cellobiose, methanol, ethanol, trehalose, pyruvate, acetate, malate, casamino acids $(0.1 \% \mathrm{w} / \mathrm{v})$, carboxymethylcellulose, amylopectin (corn), xanthan gum, locust gum (bean), guar gum, dextran, xylan (oat spelts, larch or birch), xylitol, xylose or amylose (corn and potato) [1]. Mono- and disaccharides are accumulated in AQ1.S1 $1^{\mathrm{T}}$ cultures grown in media containing konjac glucomannan, but not in sterile media that had been exposed to the same temperature as the inoculated medium or the stock of konjac glucomannan [1]. As hypothesized by Niederberger et al. [1], this most probably indicates that the konjac glucomannan is being hydrolyzed enzymatically by $\mathrm{AQ} 1 . \mathrm{S} 1^{\mathrm{T}}$ into sugars for metabolism. Removal of cystine from the growth medium does not affect cell density significantly. Hydrogen sulfide is also detected in AQ1.S1 ${ }^{\mathrm{T}}$ cultures grown in enrichment media. Strain AQ1.S1 $1^{\mathrm{T}}$ is resistant to novobiocin and streptomycin but sensitive to erythromycin, chloramphenicol and rifampicin [1].

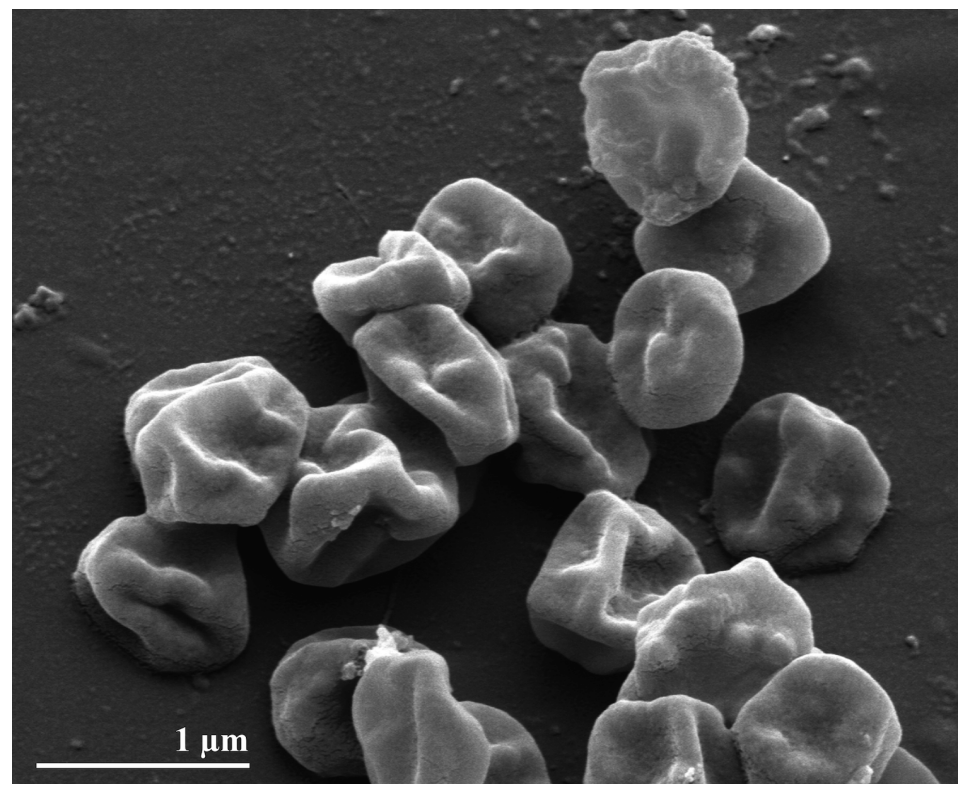

Figure 1. Scanning electron micrograph of I. aggregans AQ1.S1 


\section{Chemotaxonomy}

No chemotaxonomic data are currently available for I. aggregans strain AQ1.S1T. Also, chemotaxonomic information for the family Desulfurococcaceae is scarce. What is known is that the type species of this family, Desulfurococcus mucosus, lacks a murein cell wall and contains phytanol and polyisopreonoid dialcohols as major components of the cellular lipids [3].

Figure 2 shows the phylogenetic neighborhood of I. aggregans $\mathrm{AQ} 1 . \mathrm{S} 1^{\mathrm{T}}$ in a $16 \mathrm{~S}$ rRNA based tree. The sequence of the single $16 \mathrm{~S}$ rRNA gene copy in the genome of strain AQ1.S1 does not differ from the previously published $16 \mathrm{~S}$ rRNA sequence from DSM 17230 (DQ060321).

\section{Genome sequencing and annotation Genome project history}

This organism was selected for sequencing on the basis of its phylogenetic position [26], and is part of the Genomic Encyclopedia of Bacteria and Archaea project [27]. The genome project is deposited in the Genome OnLine Database [21] and the complete genome sequence is deposited in GenBank. Sequencing, finishing and annotation were performed by the DOE Joint Genome Institute (JGI). A summary of the project information is shown in Table 2.

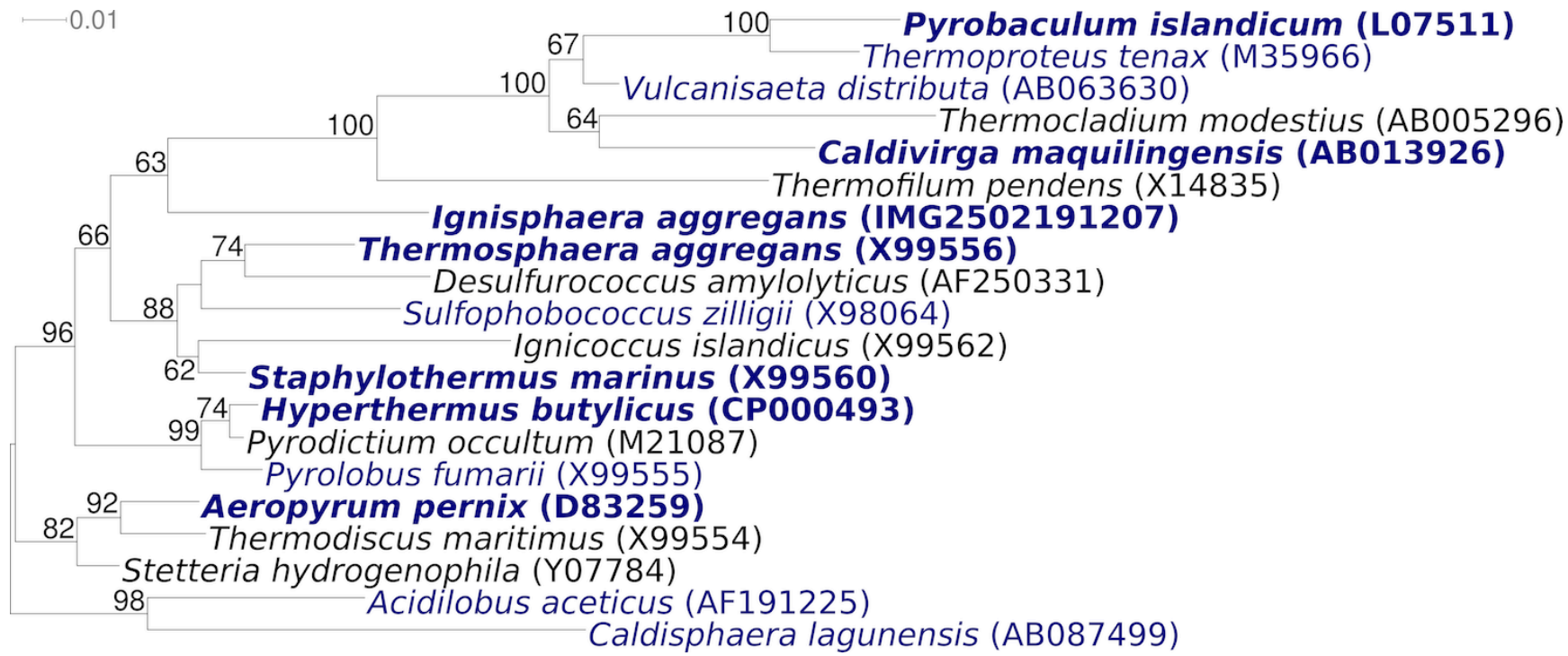

Figure 2. Phylogenetic tree highlighting the position of $I$. aggregans $A Q 1 . S 1^{\top}$ relative to the type strains of the other genera within the order Desulfurococcales. The tree was inferred from 1,329 aligned characters $[17,18]$ of the $16 \mathrm{~S}$ rRNA gene sequence under the maximum likelihood criterion [19] and rooted with the type strains of the genera of the neighboring order Acidilobales. The branches are scaled in terms of the expected number of substitutions per site. Numbers above branches are support values from 250 bootstrap replicates [20] , if greater than 60\%. Lineages with type strain genome sequencing projects registered in GOLD [21] are shown in blue, published genomes in bold ([22-25], CP000504 and CP000852).

\section{Growth conditions and DNA isolation}

I. aggregans AQ1.S1T, DSM 17230, was grown anaerobically in DSMZ medium 1043 (Ignisphaera medium) [28] at $92^{\circ} \mathrm{C}$. DNA was isolated from 0.5$1 \mathrm{~g}$ of cell paste using MasterPure Gram Positive DNA Purification Kit (Epicentre MGP04100). One $\mu \mathrm{l}$ lysozyme and five $\mu \mathrm{l}$ mutanolysin and lysostaphine, each, were added to the standard lysis solution for one hour at $37^{\circ} \mathrm{C}$ followed by $30 \mathrm{~min}$ incubation on ice after the MPC-step.

\section{Genome sequencing and assembly}

The genome of strain AQ1.S1 ${ }^{\mathrm{T}}$ was sequenced using a combination of Illumina and 454 technologies. An Illumina GAii shotgun library with reads of $152 \mathrm{Mb}$, a 454 Titanium draft library with average read length of 320 bases, and a paired end 454 library with average insert size of $15 \mathrm{~kb}$ were generated for this genome. All general aspects of library construction and sequencing can be found at http://www.jgi.doe.gov/. Illumina sequencing data was assembled with VELVET and the consensus 
sequences were shredded into $1.5 \mathrm{~kb}$ overlapped fake reads and assembled together with the 454 data. Draft assemblies were based on $177 \mathrm{Mb} 454$ draft data, and 454 paired end data. Newbler parameters are -consed - a $50-1350-\mathrm{g}-\mathrm{m}-\mathrm{ml} 20$. The initial assembly contained 20 contigs in 1 scaffold. The initial 454 assembly was converted into a phrap assembly by making fake reads from the consensus, collecting the read pairs in the 454 paired end library. The Phred/Phrap/Consed software package was used for sequence assembly and quality assessment [29] in the following finishing process. After the shotgun stage, reads were assembled with parallel phrap (High Performance
Software, LLC). Possible mis-assemblies were corrected with gapResolution, Dupfinisher [29], or sequencing cloned bridging PCR fragments with subcloning or transposon bombing (Epicentre Biotechnologies, Madison, WI). Gaps between contigs were closed by editing in Consed, by PCR and by Bubble PCR primer walks (J.-F. Chan, unpublished). A total of 32 additional reactions were necessary to close gaps and to raise the quality of the finished sequence. Illumina reads were also used to improve the final consensus quality using an in-house developed tool (the Polisher [30]). The error rate of the final genome sequence is less than 1 in 100,000.

Table 1. Classification and general features of I. aggregans AQ1.S1 ${ }^{\top}$ according to the MIGS recommendations [7]

\begin{tabular}{|c|c|c|c|}
\hline MIGS ID & Property & Term & Evidence code \\
\hline & \multirow{8}{*}{ Current classification } & Domain Archaea & TAS [8] \\
\hline & & Phylum Crenarchaeota & TAS $[9,10]$ \\
\hline & & Class Thermoprotei & TAS $[10,11]$ \\
\hline & & Order Desulfurococcales & TAS $[10,12]$ \\
\hline & & Family Desulfurococcaceae & TAS $[2,3-5]$ \\
\hline & & Genus Ignisphaera & TAS [1] \\
\hline & & Species Ignisphaera aggregans & TAS [1] \\
\hline & & Type strain AQ1.S1 & TAS [1] \\
\hline & Gram stain & not reported & \\
\hline & Cell shape & $\begin{array}{l}\text { regular or irregular cocci that occur singly, in } \\
\text { pairs or in aggregates }\end{array}$ & TAS [1] \\
\hline & Motility & none & NAS \\
\hline & Sporulation & not reported & \\
\hline & Temperature range & $85^{\circ} \mathrm{C}-98^{\circ} \mathrm{C}$ & TAS [1] \\
\hline & Optimum temperature & $92-95^{\circ} \mathrm{C}$ & TAS [1] \\
\hline & Salinity & $<0.5 \% \mathrm{NaCl}$ & TAS [1] \\
\hline \multirow[t]{3}{*}{ MIGS-22 } & Oxygen requirement & obligate anaerobic & TAS [1] \\
\hline & Carbon source & $\begin{array}{l}\text { starch, trypticase, peptone, lactose, glucose, } \\
\text { konjac glucomannan, amongst others (see text) }\end{array}$ & TAS [1] \\
\hline & Energy source & carbohydrates, amino acids & TAS [1] \\
\hline MIGS-6 & Habitat & boiling spring & TAS [1] \\
\hline MIGS-15 & Biotic relationship & free-living & TAS [1] \\
\hline \multirow[t]{3}{*}{ MIGS-14 } & Pathogenicity & none & TAS [13] \\
\hline & Biosafety level & 1 & TAS [13] \\
\hline & Isolation & pool water & TAS [14] \\
\hline MIGS-4 & Geographic location & Kuirau Park, Rotorau, New Zealand & TAS [1] \\
\hline MIGS-5 & Sample collection time & 2002 & TAS [1] \\
\hline MIGS-4.1 & Latitude & 176.24 & TAS [14] \\
\hline MIGS-4.2 & Longitude & -38.13 & TAS [14] \\
\hline MIGS-4.3 & Depth & $\leq 2 \mathrm{~m}$ & TAS [14] \\
\hline MIGS-4.4 & Altitude & $268 \mathrm{~m}$ & NAS \\
\hline
\end{tabular}

Evidence codes - IDA: Inferred from Direct Assay (first time in publication); TAS: Traceable Author Statement (i.e., a direct report exists in the literature); NAS: Non-traceable Author Statement (i.e., not directly observed for the living, isolated sample, but based on a generally accepted property for the species, or anecdotal evidence). These evidence codes are from of the Gene Ontology project [15]. If the evidence code is IDA, then the property was directly observed by one of the authors or an expert mentioned in the acknowledgements. 
Table 2. Genome sequencing project information

\begin{tabular}{|c|c|c|}
\hline MIGS ID & Property & Term \\
\hline MIGS-31 & Finishing quality & Finished \\
\hline MIGS-28 & Libraries used & $\begin{array}{l}\text { Three genomic libraries: one } 454 \text { pyrose- } \\
\text { quence standard library, one } 454 \text { paired } \\
\text { end } 15 \text { kb library, and one Illumina library }\end{array}$ \\
\hline MIGS-29 & Sequencing platforms & 454 Titanium; Illumina GAii \\
\hline MIGS-31.2 & Sequencing coverage & $94.5 \times$ pyrosequence and Illumina \\
\hline MIGS-30 & Assemblers & $\begin{array}{l}\text { Newbler version 2.0.00.20- PostRelease- } \\
11-05-2008 \text {-gcc-3.4.6/, phrap, Velvet }\end{array}$ \\
\hline \multirow[t]{6}{*}{ MIGS-32 } & Gene calling method & Prodigal 1.4, GenePRIMP \\
\hline & INSDC ID & СР002098 \\
\hline & Genbank Date of Release & August 24, 2010 \\
\hline & GOLD ID & Gc01330 \\
\hline & NCBI project ID & 33361 \\
\hline & Database: IMG-GEBA & 2502171146 \\
\hline \multirow[t]{2}{*}{ MIGS-13 } & Source material identifier & DSM 17230 \\
\hline & Project relevance & Tree of Life, GEBA \\
\hline
\end{tabular}

\section{Genome annotation}

Genes were identified using Prodigal [31] as part of the Oak Ridge National Laboratory genome annotation pipeline, followed by a round of manual curation using the JGI GenePRIMP pipeline [32]. The predicted CDSs were translated and used to search the National Center for Biotechnology Information (NCBI) nonredundant database, UniProt, TIGRFam, Pfam, PRIAM, KEGG, COG, and InterPro databases. Additional gene prediction analysis and functional annotation was performed within the Integrated Microbial Genomes - Expert Review (IMG-ER) platform [33].

\section{Genome properties}

The genome consists of a 1,875,953 bp long chromosome with a $35.7 \% \mathrm{G}+\mathrm{C}$ content (Table 3 and Figure 3). Of the 2,061 genes predicted, 2,009 were protein-coding genes, and 52 RNAs; 79 pseudogenes were also identified. The majority of the protein-coding genes (56.2\%) were assigned a putative function while the remaining ones were annotated as hypothetical proteins. The distribution of genes into COGs functional categories is presented in Table 4.

Table 3. Genome Statistics

\begin{tabular}{lrr}
\hline Attribute & Value & \% of Total \\
\hline Genome size (bp) & $1,875,953$ & $100.00 \%$ \\
DNA coding region (bp) & $1,623,145$ & $86.52 \%$ \\
DNA G+C content (bp) & 669,463 & $35.69 \%$ \\
Number of replicons & 1 & \\
Extrachromosomal elements & 0 & \\
Total genes & 2,061 & $100.00 \%$ \\
RNA genes & 52 & $2.52 \%$ \\
rRNA operons & 1 & \\
Protein-coding genes & 2,009 & $97.48 \%$ \\
Pseudo genes & 79 & $3.83 \%$ \\
Genes with function prediction & 1,158 & $56.19 \%$ \\
Genes in paralog clusters & 190 & $9.22 \%$ \\
Genes assigned to COGs & 1,220 & $59.19 \%$ \\
Genes assigned Pfam domains & 1,280 & $62.11 \%$ \\
Genes with signal peptides & 147 & $7.13 \%$ \\
Genes with transmembrane helices & 454 & $22.03 \%$ \\
CRISPR repeats & 9 & \\
\hline
\end{tabular}




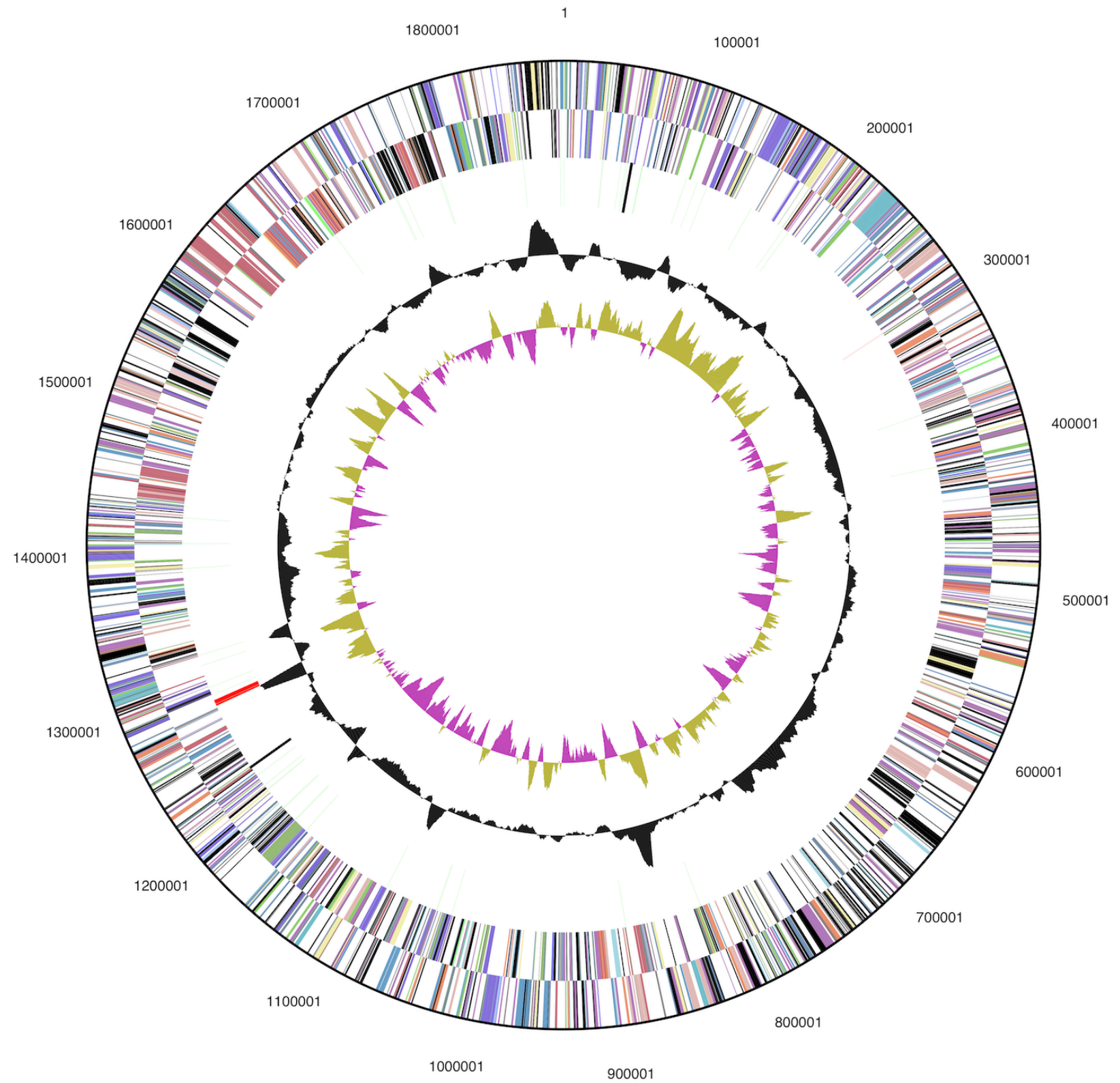

Figure 3. Graphical circular map of the genome. From outside to the center: Genes on forward strand (color by COG categories), Genes on reverse strand (color by COG categories), RNA genes (tRNAs green, rRNAs red, other RNAs black), GC content, GC skew.

\section{Insights from the genome sequence}

Even though the tree depicted in Figure 1 is not particularly well resolved, the fact that I. aggregans does not cluster with the Desulfurococcaceae in $16 \mathrm{~S}$ rRNA gene sequence-based phylogenies calls for a more detailed whole-genome-based analysis [34]. Both, in Figure 1 and in the AllSpecies-Living-Tree [35], I. aggregans is located deep on the branch leading to the Thermoproteaceae (and Sulfolobaceae). By circumstance, the class Thermoprotei within the phylum Crenarchaeota already offers a reasonably large set of reference genomes required for such an analysis.
We thus assembled a dataset comprising all publicly available genomes from the set of organisms represented in the $16 \mathrm{~S}$ rRNA tree (Fig. 1). Pairwise distances were calculated using the GBDP algorithm [36,37], which has recently been used to mimic DNA-DNA-hybridization values $[37,38]$. Here we applied the logarithmic version of formula (3) in $[34,38]$. The NeighborNet algorithm as implemented in SplitsTree version 4.10 [39] was used to infer a phylogenetic network from the distances, which is shown in Fig. 4. 
Table 4. Number of genes associated with the general COG functional categories

\begin{tabular}{lrrl}
\hline Code & value & \%age & Description \\
\hline J & 158 & 11.9 & Translation, ribosomal structure and biogenesis \\
A & 2 & 0.2 & RNA processing and modification \\
K & 64 & 4.8 & Transcription \\
L & 70 & 5.3 & Replication, recombination and repair \\
B & 2 & 0.2 & Chromatin structure and dynamics \\
D & 9 & 0.7 & Cell cycle control, cell division, chromosome partitioning \\
Y & 0 & 0.0 & Nuclear structure \\
V & 22 & 1.7 & Defense mechanisms \\
T & 23 & 1.7 & Signal transduction mechanisms \\
M & 31 & 2.3 & Cell wall/membrane/envelope biogenesis \\
N & 11 & 0.8 & Cell motility \\
Z & 0 & 0.0 & Cytoskeleton \\
W & 0 & 0.0 & Extracellular structures \\
U & 16 & 1.2 & Intracellular trafficking, secretion, and vesicular transport \\
O & 56 & 4.2 & Posttranslational modification, protein turnover, chaperones \\
C & 82 & 6.2 & Energy production and conversion \\
G & 80 & 6.0 & Carbohydrate transport and metabolism \\
E & 135 & 10.2 & Amino acid transport and metabolism \\
F & 46 & 3.5 & Nucleotide transport and metabolism \\
H & 64 & 4.8 & Coenzyme transport and metabolism \\
I & 13 & 1.0 & Lipid transport and metabolism \\
P & 89 & 6.7 & Inorganic ion transport and metabolism \\
Q & 4 & 0.3 & Secondary metabolites biosynthesis, transport and catabolism \\
R & 209 & 15.8 & General function prediction only \\
S & 140 & 10.6 & Function unknown \\
- & 841 & 40.8 & Not in COGs \\
\hline & & & \\
\hline
\end{tabular}

The results indicate that the placement of I. aggregans as sister group of Thermoproteales (Fig. 1) is an artifact of the 16S rRNA analysis. The wholegenome network, while showing some conflicting signal close to the backbone, is in agreement with the splitting of the considered genera into the orders Desulfurococcales and Thermoproteales. However, the analysis provides some evidence that Aeropyrum pernix (Desulfurococcaceae) is more closely related to Pyrodictiaceae (represented by Hyperthermus and Pyrolobus) than to the remaining Desulfurococcaceae. The numerous additional type strain genome sequencing projects in the Desulfurococcales (Fig. 1) are likely to shed even more light on the phylogenetic relationships within this group by enabling future whole-genome phylogenies based on many more taxa.
A separate status of I. aggregans within the Desulfurococcaceae is supported by a lack of genes encoding membrane-bound multienzyme complexes that are thought to participate in the energy metabolism of members of this group. Operons encoding a MBX-related ferredoxin-NADPH oxidoreductase and a dehydrogenase-linked MBX complex are lacking in I. aggregans, although both are present in the completed genome sequences of Thermosphaera aggregans [24], Staphylothermus marinus [25] and Desulfurococcus kamchatkensis. The genome of $A$. pernix also lacks genes for the MBH-related energy-coupling hydrogenase, which are found in most members of the Desulfurococcaceae including I. aggregans (Igag_1902 - Igag_1914). 


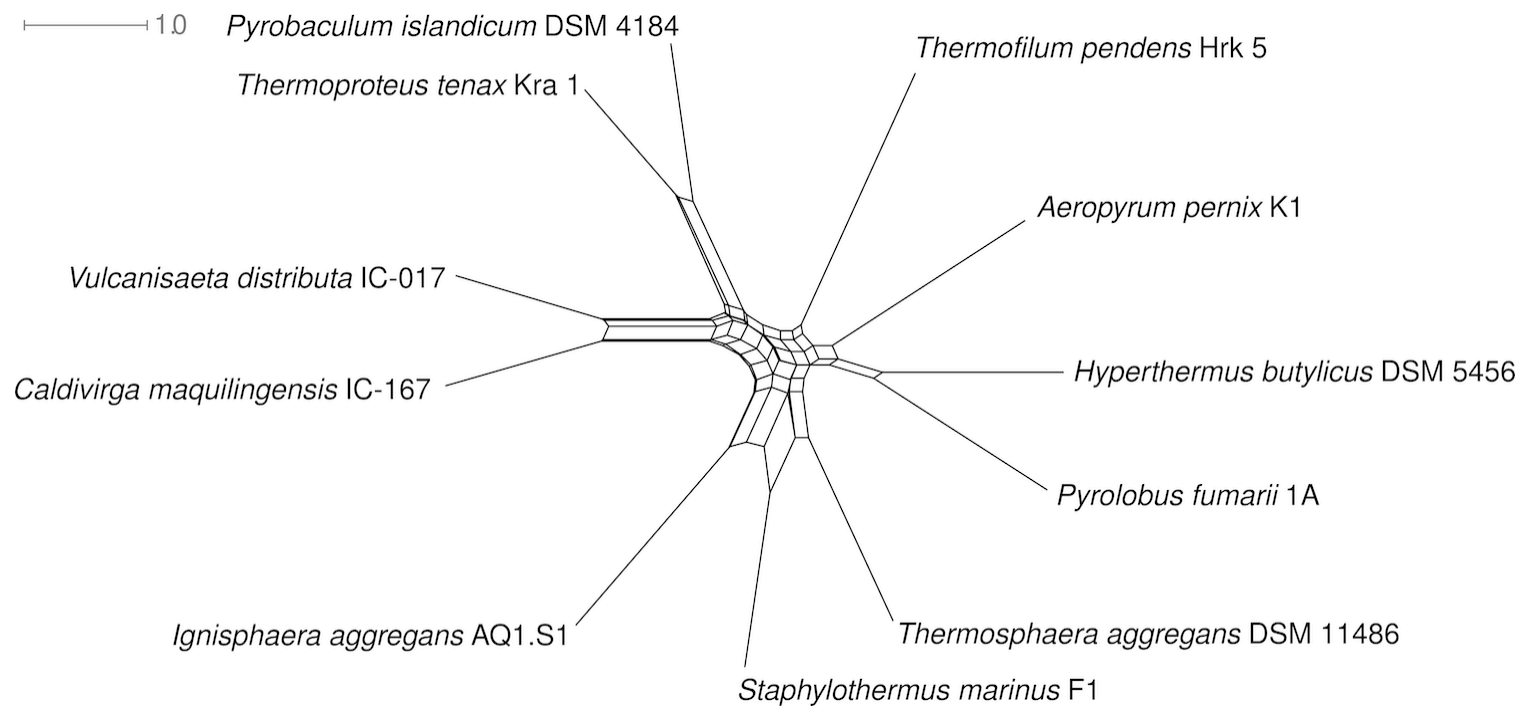

Figure 4. Phylogenetic network inferred from whole-genome (GBDP) distances, showing the relationships between Desulfurococcaceae (Aeropyrum, Ignisphaera, Staphylothermus and Thermosphaera), Pyrodictiaceae (Hyperthermus and Pyrolobus), Thermoproteaceae (Caldivirga, Pyrobaculum, Thermoproteus and Vulcanisaeta) and Thermofilaceae (Thermofilum).

\section{Acknowledgements}

We would like to gratefully acknowledge the help of Maren Schröder (DSMZ) for growth of I. aggregans and the help of Alexander Auch (Tübingen, Germany) in creating a local version of the GBDP software. This work was performed under the auspices of the US Department of Energy Office of Science, Biological and Environmental Research Program, and by the University of California, Lawrence Berkeley National Laboratory under contract No. DE-AC02-05CH11231, Lawrence

\section{References}

1. Niederberger TD, Götz DK, McDonald IR, Ronimus RS, Morgan HW. Ignisphaera aggregans gen. nov., sp. nov., a novel hyperthermophilic crenarchaeote isolated from hot springs in Rotorua and Tokaanu, New Zealand. Int J Syst Evol Microbiol 2006; 56:965-971. PubMed doi:10.1099/ijs.0.63899-0

2. Validation of the publication of new names and new combinations previously effectively published outside the IJSB. List no. 10. Int I Syst Bacteriol 1983; 33:438-440. doi:10.1099/00207713$\underline{33-2-438}$

3. Zillig W, Stetter KO, Prangishvilli D, Schäfer W, Wunderl S, Janekovic D, Holz I, Palm P. Desulfurococcaceae, the second family of the extremely thermophilic, anaerobic, sulfur-respiring Thermoproteales. Zentralbl Bakteriol Parasitenkd Infektionskr Hyg Abt 1982; 1 Orig. C:304-317.
Livermore National Laboratory under Contract No. DEAC52-07NA27344, and Los Alamos National Laboratory under contract No. DE-AC02-06NA25396, UTBattelle and Oak Ridge National Laboratory under contract DE-AC05-000R22725, as well as German Research Foundation (DFG) INST 599/1-2 and SI 1352/12 and Thailand Research Fund Royal Golden Jubilee Ph.D. Program No. PHD/0019/2548 for MY.

4. List Editor. Validation List no. 10. Validation of the publication of new names and new combinations previously effectively published outside the IJSB. Int I Syst Bacteriol 1983; 33:438-440. doi:10.1099/00207713-33-2-438

5. Burggraf S, Huber H, Stetter KO. Reclassification of the crenarchael orders and families in accordance with $16 \mathrm{~S}$ rRNA sequence data. Int I Syst Bacteriol 1997; 47:657-660. PubMed doi:10.1099/00207713-47-3-657

6. Chun J, Lee JH, Jung Y, Kim M, Kim S, Kim BK, Lim YW. EzTaxon: a web-based tool for the identification of prokaryotes based on $16 \mathrm{~S}$ ribosomal RNA gene sequences. Int / Syst Evol Microbiol 2007; 57:2259-2261. PubMed doi:10.1099/ijs.0.64915-0

7. Field D, Garrity G, Gray T, Morrison N, Selengut J, Sterk P, Tatusova T, Thomson N, Allen MJ, An- 
giuoli SV, et al. The minimum information about a genome sequence (MIGS) specification. Nat Biotechnol 2008; 26:541-547. PubMed doi:10.1038/nbt1360

8. Woese CR, Kandler O, Wheelis ML. Towards a natural system of organisms: proposal for the domains Archaea, Bacteria, and Eucarya. Proc Natl Acad Sci USA 1990; 87:4576-4579. doi:10.1073/pnas.87.12.4576

9. Garrity GM, Holt JG. 2001. The Road Map to the Manual In G. M. Garrity, D. R. Boone, and R. W. Castenholz (ed.), Bergey's Manual of Systematic Bacteriology, 2 ed, vol. 1. Springer, New York.

10. List Editor. Validation List no. 85. Validation of publication of new names and new combinations previously effectively published outside the IJSEM. Int J Syst Evol Microbiol 2002; 52:685-690. PubMed doi:10.1099/ijs.0.02358-0

11. Reysenbach AL. 2001. Class I. Thermoprotei class. nov., p. 169. In GM Garrity, DR Boone, and RW Castenholz (eds), Bergey's Manual of Systematic Bacteriology, 2 ed, vol. 1. Springer, New York.

12. Huber H, Stetter O. 2001. Order II. Desulfurococcales ord. nov., p. 179-180. In G. M. Garrity, D. R. Boone, and R. W. Castenholz (ed.), Bergey's Manual of Systematic Bacteriology, 2 ed, vol. 1. Springer, New York.

13. Classification of Bacteria and Archaea in risk groups. http://www.baua.de TRBA 466.

14. Niederberger TD, Ronimus RS, Morgan HW. The microbial ecology of a high-temperature nearneutral spring situated in Rotorua, New Zealand. Microbiol Res 2008; 163:594-603. PubMed doi:10.1016/j.micres.2006.09.001

15. Ashburner M, Ball CA, Blake JA, Botstein D, Butler H, Cherry JM, Davis AP, Dolinski K, Dwight SS, Eppig JT, et al. Gene Ontology: tool for the unification of biology. Nat Genet 2000; 25:25-29. $\underline{\text { PubMed doi:10.1038/75556 }}$

16. Benson DA, Karsch-Mizrachi I, Lipman DJ, Ostell J, Sayers EW. GenBank. Nucleic Acids Res 2009; 37:D26-D31. PubMed doi:10.1093/nar/gkn723

17. Castresana J. Selection of conserved blocks from multiple alignments for their use in phylogenetic analysis. Mol Biol Evol 2000; 17:540-552. PubMed

18. Lee C, Grasso C, Sharlow MF. Multiple sequence alignment using partial order graphs. Bioinformatics 2002; 18:452-464. PubMed doi:10.1093/bioinformatics/18.3.452
19. Stamatakis A, Hoover P, Rougemont J. A Rapid Bootstrap Algorithm for the RAxML Web Servers. Syst Biol 2008; 57:758-771. PubMed doi:10.1080/10635150802429642

20. Pattengale ND, Alipour M, Bininda-Emonds ORP, Moret BME, Stamatakis A. How many bootstrap replicates are necessary? Lect Notes Comput Sci 2009; 5541:184-200. doi:10.1007/978-3-64202008-7_13

21. Liolios K, Chen IM, Mavromatis K, Tavernarakis N, Hugenholtz P, Markovitzz VM, Kyrpides NC. The Genomes On Line Database (GOLD) in 2009: status of genomic and metagenomic projects and their associated metadata. Nucleic Acids Res 2010; 38:D346-D354. PubMed doi:10.1093/nar/gkp848

22. Brügger $K$, Chen $L$, Stark $M$, Zibat $A$, Redder $P$, Ruepp A, Awayez M, She Q, Garrett RA, Klenk HP. The genome of Hyperthermus butylicus: a sulfur-reducing, peptide fermenting, neutrophilic crenarchaeote growing up to $108^{\circ} \mathrm{C}$. Archaea 2007; 2:127-135. PubMed doi:10.1155/2007/745987

23. Kawarabayasi $Y$, Hino $Y$, Horikawa $H$, Yamazaki S, Haikawa Y, Jin-no K, Takahashi M, Sekine M, Baba S, Ankai A, et al. Complete genome sequence of an aerobic hyperthermophilic crenarchaeon, Aeropyrum pernix K1. DNA Res 1999; 6:83-101, 145-152. PubMed doi:10.1093/dnares/6.2.83

24. Spring S, Rachel R, Lapidus A, Davenport K, Tice H, Copeland A, Cheng JF, Lucas S, Chen F, Nolan $\mathrm{M}$, et al. Complete genome sequence of Thermosphaera aggregans type strain $\left(\mathrm{M}_{11} 1 \mathrm{TL}^{\top}\right)$. Stand Genomic Sci 2010; 2:245-259. doi:10.4056/sigs.821804

25. Anderson IJ, Dharmarajan L, Rodriguez J, Hooper S, Porat I, Ulrich LE, Elkins JG, Mavromatis K, Sun $\mathrm{H}$, Land $\mathrm{M}$, et al. Complete genome sequence of Staphylothermus marinus reveals differences in sulfur metabolism among heterotrophic Crenarchaeota. BMC Genomics 2009; 10:145. PubMed doi:10.1186/1471-2164-10-145

26. Klenk HP, Göker M. En route to a genome-based classification of Archaea and Bacteria? Syst Appl Microbiol 2010; 33:175-182. PubMed doi:10.1016/j.syapm.2010.03.003

27. Wu D, Hugenholtz P, Mavromatis K, Pukall R, Dalin E, Ivanova NN, Kunin V, Goodwin L, Wu $M$, Tindall BJ, et al. A phylogeny-driven genomic encyclopaedia of Bacteria and Archaea. Nature 
2009; 462:1056-1060. PubMed

doi:10.1038/nature08656

28. List of growth media used at DSMZ: http://www.dsmz.de/microorganisms/media_list.p hp.

29. Sims D, Brettin T, Detter J, Han C, Lapidus A, Copeland A, Glavina Del Rio T, Nolan M, Chen F, Lucas $\mathrm{S}$, et al. Complete genome sequence of $\mathrm{Ky}$ tococcus sedentarius type strain $\left(541^{\mathrm{T}}\right)$. Stand Genomic Sci 2009; 1:12-20. doi:10.4056/sigs.761

30. Lapidus A, LaButti K, Foster B, Lowry S, Trong S, Goltsman E. POLISHER: An effective tool for using ultra short reads in microbial genome assembly and finishing. AGBT, Marco Island, FL, 2008.

31. Hyatt D, Chen GL, Locascio PF, Land ML, Larimer FW, Hauser LJ. Prodigal Prokaryotic Dynamic Programming Genefinding Algorithm. BMC Bioinformatics 2010; 11:119. PubMed doi:10.1186/1471-2105-11-119

32. Pati A, Ivanova N, Mikhailova N, Ovchinikova G, Hooper SD, Lykidis A, Kyrpides NC. GenePRIMP: A gene prediction improvement pipeline for $\mathrm{mi}-$ crobial genomes. Nat Methods 2010; 7:455-457. PubMed doi:10.1038/nmeth.1457

33. Markowitz VM, Ivanova NN, Chen IMA, Chu K, Kyrpides NC. IMG ER: a system for microbial genome annotation expert review and curation. Bioinformatics 2009; 25:2271-2278. PubMed doi:10.1093/bioinformatics/btp393
34. Auch AF, Klenk HP, Göker M. Standard operating procedure for calculating genome-to-genome distances based on high-scoring segment pairs. Stand Genomic Sci 2010; 2:142-148. doi:10.4056/sigs.541628

35. Yarza P, Richter M, Peplies J, Euzeby J, Amann R, Schleifer KH, Ludwig W, Glöckner FO, RossellóMóra R. The All-Species Living Tree project: A $16 \mathrm{~S}$ rRNA-based phylogenetic tree of all sequenced type strains. Syst Appl Microbiol 2008; 31:241-250. PubMed doi:10.1016/j.syapm.2008.07.001

36. Henz SR, Huson DH, Auch AF, Nieselt-Struwe K, Schuster SC. Whole-genome prokaryotic phylogeny. Bioinformatics 2005; 21:2329-2335. PubMed doi:10.1093/bioinformatics/bth324

37. Auch AF, Henz SR, Holland BR, Göker M. Genome BLAST distance phylogenies inferred from whole plastid and whole mitochondrion genome sequences. BMC Bioinformatics 2006; 7:350. PubMed doi:10.1186/1471-2105-7-350

38. Auch AF, von Jan M, Klenk HP, Göker M. Digital DNA-DNA hybridization for microbial species delineation by means of genome-to-genome sequence comparison. Stand Genomic Sci 2010; 2:117-134. doi:10.4056/sigs.531120

39. Huson DH, Bryant D. Application of Phylogenetic Networks in Evolutionary Studies. Mol Biol Evol 2005; 23:254-267. PubMed doi:10.1093/molbev/msj030 